\title{
Gender differences of morphological and hemodynamic characteristics of abdominal aortic aneurysm
}

Zujie Gao ${ }^{1 \dagger}$, Jiang Xiong ${ }^{2 \dagger}$, Zengsheng Chen ${ }^{1}$, Xiaoyan Deng ${ }^{1}$, Zaipin $\mathrm{Xu}^{3}$, Anqiang Sun ${ }^{1 *}$ (D) and Yubo Fan ${ }^{14^{*}}$

\begin{abstract}
Background: Gender difference in cardiovascular diseases (CVDs) is an important topic in the field of cardiovascular medicine. In this study, we focused on the mortality difference of abdominal aortic aneurysms (AAA), which is higher for female than that of male. The aim of this study was to verify whether morphological and hemodynamic factors play their roles in this phenomenon.

Methods: Patient-specific AAA models of 11 females and 23 males with similar age and body mass index (BMI) have been reconstructed based on clinical computed tomography $(C T)$ data. Firstly, the morphological parameters (diameters, curvature, intraluminal thrombus volume, etc.) of AAA models and lumbar vertebrae models were collected and analyzed. Then, based on statistical results of morphological parameters, uniformed male and female AAA models were reconstructed, and hemodynamic simulations were conducted respectively. In post-processing, the hemodynamic performances induced by gender-different morphological geometries were analyzed and compared.
\end{abstract}

Results: The comparison of morphological parameters revealed that the average curvature of lumbar vertebrae and AAA centerline of female AAA models were obviously higher than that of the male. The amount of intraluminal thrombus in female AAA models was relatively lower than that of the male. According to the hemodynamic simulation, the uniform female AAA model has higher peak pressure, lower oscillatory shear stress index (OSI), and lower relative residence time (RRT) than that of the male model, all of which put female AAA to a relatively higher risk hemodynamic situation.

Conclusions: The morphological and hemodynamic features of AAA have very obvious gender differences that would induce higher risk of rupture for female AAA biomechanically. These findings would help to explore the mechanism of gender differences in AAA and draw attention to gender-specific consideration for AAA treatment. More morphological and hemodynamic indictors are suggested to be involved in the future guidelines.

Keywords: Gender difference, Abdominal aortic aneurysm, Hemodynamics, Morphological

\footnotetext{
* Correspondence: saq@buaa.edu.cn; yubofan@buaa.edu.cn

${ }^{\dagger}$ Zujie Gao and Jiang Xiong contributed equally to this work.

'School of Biological Science and Medical Engineering, Beijing Advanced

Innovation Center for Biomedical Engineering, Key Laboratory for

Biomechanics and Mechanobiology of Ministry of Education, Beihang

University, Beijing 100083, China

Full list of author information is available at the end of the article
}

(C) The Author(s). 2020 Open Access This article is licensed under a Creative Commons Attribution 4.0 International License, which permits use, sharing, adaptation, distribution and reproduction in any medium or format, as long as you give appropriate credit to the original author(s) and the source, provide a link to the Creative Commons licence, and indicate if changes were made. The images or other third party material in this article are included in the article's Creative Commons licence, unless indicated otherwise in a credit line to the material. If material is not included in the article's Creative Commons licence and your intended use is not permitted by statutory regulation or exceeds the permitted use, you will need to obtain permission directly from the copyright holder. To view a copy of this licence, visit http://creativecommons.org/licenses/by/4.0/. The Creative Commons Public Domain Dedication waiver (http://creativecommons.org/publicdomain/zero/1.0/) applies to the data made available in this article, unless otherwise stated in a credit line to the data. 


\section{Background}

Gender differences of cardiovascular diseases (CVDs) between female and male have been reported and discussed by recent literatures [1]. Abdominal aortic aneurysm (AAA) is one of the typical gender-related aorta diseases. AAA is a degenerative disease manifested by an irreversible enlargement in the abdominal aorta which has been regarded as one of the most threatening diseases for elder people ( $>65$ years old) [2]. Rupture is a dangerous event for AAA, with a mortality rate exceeding $80 \%$ [3]. The rupture rate of AAA in female is more than 4 times that of male [4-6].

Although the gender difference of AAA has been validated by multiple statistical meta-analysis [7], its mechanism is still unclear and has not been considered in most current surgical decision-making guidelines. The ignorance of gender differences in the clinical procedure would cause an unpredictable influence on the survival rate and quality of life of AAA patients. Understanding AAA gender differences would help make more accurate surgical decisions for patients.

Previous studies have found that hemodynamic factors play a significant role in the growth and rupture of AAA [8]. Blood pressure, peak wall stress (PWS), oscillatory of flow velocity, etc. have been confirmed as key factors affecting AAA physiology and pathology [9, 10]. Meanwhile, various studies have shown that the gender difference in the risk of AAA rupture might be caused not only by physiological factors (such as LDL and sex hormone) [11-13] but also by anatomical factors [14] (such as the body size and the diameter of the aorta [15]). Therefore, the present study hypothesized that the differences in anatomical structure between female and male would influence the hemodynamics in the AAA which might induce different biological consequences.

In the present study, in order to further explore the mechanism of AAA gender differences, the morphology and hemodynamic differences between male and female were investigated, and some morphological and hemodynamic indictors have been found that may be related to the AAA gender differences.

\section{Methods}

\section{Patients}

In total, 11 female and 23 male patients diagnosed with AAA by computed tomography (CT) scans (shown in Fig. 1a) in the Chinese PLA General Hospital between 2017 and 2018 were randomly selected. Patient demographic information (age, weight, height, blood pressure, and the heart rate), AAA risk factors (cardiovascular disease (such as coronary artery heart disease and cerebral infarction), hypertension, diabetes, smoking history, and chronic obstructive pulmonary diseases (COPD)), and biochemical information (hemoglobin, total cholesterol, triglycerides, high-density lipoprotein cholesterol, and low-density lipoprotein cholesterol) are shown in Table 1. Body mass index (BMI) and body surface area (BSA) were calculated by height and weight, where the BMI was defined as [15]

$$
\mathrm{BMI}=\frac{\text { weight }(\mathrm{kg})}{\text { height }^{2}\left(\mathrm{~m}^{2}\right)}
$$

BSA was defined as [16]

$$
\begin{aligned}
\mathrm{BSA}= & 0.20247 \\
& \times\left[\operatorname{weight}(\mathrm{kg})^{0.425} \times \operatorname{height}(\mathrm{m})^{0.725}\right]
\end{aligned}
$$

There is no difference in average age $(72.6$ vs 72.9 years; $p=0.901)$ or average BMI $\left(24.9 \mathrm{vs} 23.7 \mathrm{~kg} \cdot \mathrm{m}^{-2} ; p\right.$ $=0.278$ ) between females and males (Table 1). Systolic pressure, diastolic pressure, and heart rate were the same for females and males. Some common complications of AAA, such as cardiovascular disease, hypertension, and COPD, are not significantly different between genders. Diabetes which is considered a protective factor for AAA [17] is more common among females (38.5\% vs $11.15 \% ; p=0.044)$. Clinical details are also summarized in Table 1.

\section{AAA model reconstruction}

The CT images were obtained via a dual-source CT scanner (SOMATOM Definition Flash, SIEMENS, Germany) with injection of 70 90 ml of contrast agent with $50 \mathrm{ml}$ of saline chaser, threshold $80 \mathrm{HU}$; rotation speed $500 \mathrm{~ms}$; collimation 64; slice $1.0 \mathrm{~mm}$; pitch 1.0; voltage $100 \mathrm{kV}$; current $200 \sim 350 \mathrm{~mA}$; image resolution $512 \times 512$; and slice increment $0.699 \mathrm{~mm}$. The CT data were imported into the Mimics software (v9.0, Materialise, Ann Arbor, MI, Belgium) for segmentation, and the abdominal aorta, lumbar vertebra, and blood were identified by the grayscale division shown in Fig. 1b. The reconstructed AAA models and lumbar vertebrae models are shown in Fig. 1c. All the reconstructed AAA models are shown in Fig. 1d.

\section{Morphological parameter extraction}

Based on the models reconstructed above, the morphological parameters were measured, as shown in Fig. 2, including the diameters of the AAA (Fig. 2a), the lumbar vertebrae curve (Fig. 2b), the centerline of AAA (Fig. 2c), and the thrombus volume (Fig. 2d). The aneurysm length was measured axially from the renal artery bifurcation to the aortic bifurcation.

According to the diameter information, two indicators which are commonly used to measure the risk of rupture were calculated. One is defined as the ratio of the 
a.

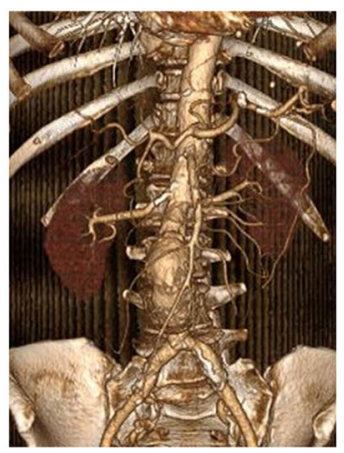

d.

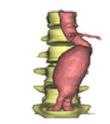

FAAA-001

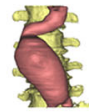

FAAA-009

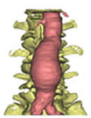

MAAA-004

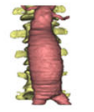

MAAA-012

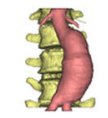

MAAA-019

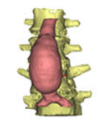

FAAA-002

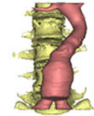

FAAA- 010

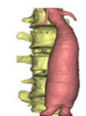

MAAA-005

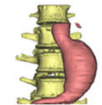

MAAA-013

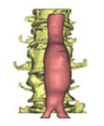

MAAA-020 b.
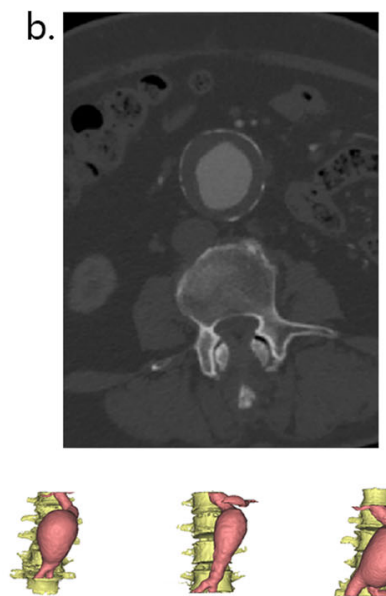

FAAA-004

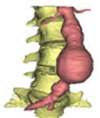

FAAA-011

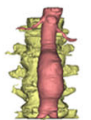

MAAA-006

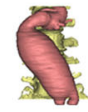

MAAA-014

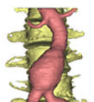

MAAA-021

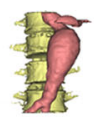

FAAA-005

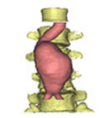

FAAA-013

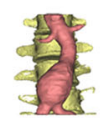

MAAA-007
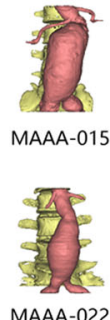

c.
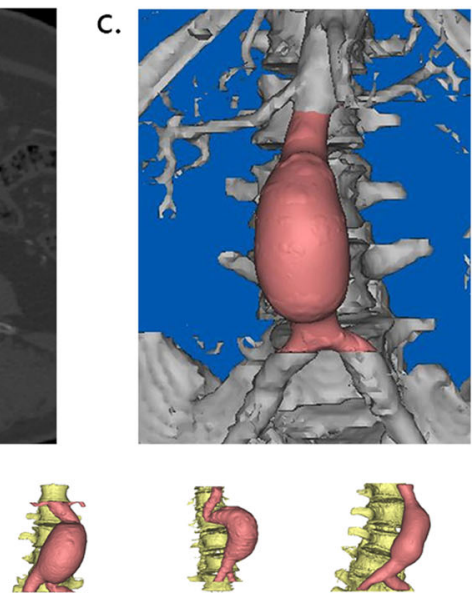

FAAA-006

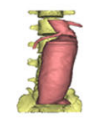

MAAA-001

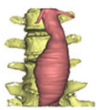

MAAA-008

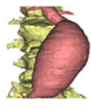

MAAA-016

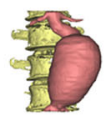

MAAA-023

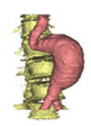

FAAA-007

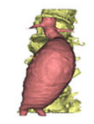

MAAA-002

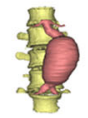

MAAA-009

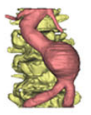

MAAA-017
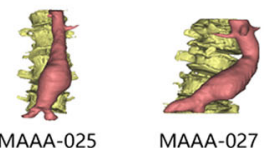

Fig. 1 Segmentation and 3D reconstruction of AAA. a Abdominal computed tomography (CT) imaging, supported by the RadiAnt software. b Segmentation of lumbar vertebrae, blood, and blood vessels by grayscale and anatomy (cross section). c Reconstructed abdominal aorta (shown in pink) in the Mimics software. $\mathbf{d}$ All AAA models used in this study.

maximum diameter to the diameter of the proximal normal aorta $[18,19]$ expressed as the expansion factor:

$$
\text { Expansion factor }=\frac{\text { the maximum diameter of AAA }}{\text { proximal normal aorta diameter }}
$$

The other one is aortic size index (ASI) [20] defined as

$$
\mathrm{ASI}=\frac{\text { aneurysm diameter }(\mathrm{cm})}{\mathrm{BSA}\left(\mathrm{m}^{2}\right)}
$$

The lumbar vertebrae curve was obtained by connecting the anterior midpoint of the five lumbar vertebrae $\left(\mathrm{L}_{1} \sim \mathrm{L}_{5}\right)$ in dark blue, as shown in Fig. $2 \mathrm{~b}$. The centerline was calculated by the medCAD function of the Mimics software with a smooth factor of 0.5 shown in Fig. $2 \mathrm{c}$ as dark red line. Based on the above curves, the projection of the curve on the sagittal plane was obtained, and the curvature was calculated.

The total volume of abdominal aortic aneurysm $\left(V_{\mathrm{a}}\right)$ and the volume of blood $\left(V_{\mathrm{b}}\right)$ were used to calculate intraluminal thrombus (ILT) percentage volume. The calculation formula is as follows:

$$
\text { ILT percentage volume }=\frac{\left(V_{\mathrm{a}}\right)-\left(V_{\mathrm{b}}\right)}{\left(V_{\mathrm{a}}\right)}
$$

In Fig. $2 \mathrm{~d}, V_{\mathrm{a}}$ is shown in pink, and $V_{\mathrm{b}}$ is shown in dark red.

\section{Uniform model generation}

Since each AAA case model has its specific geometry, in order to analyze the common hemodynamic performances of each gender, the unified model of male and 
Table 1 Clinical data of all patients

\begin{tabular}{llll}
\hline Gender & Female $(n=11)$ & Male $(n=23)$ & $p$ \\
\hline Age $($ year $)$ & $72.6 \pm 8.2$ & $72.9 \pm 3.6$ & 0.901 \\
BMI $\left(\mathrm{kg} \cdot \mathrm{m}^{-2}\right)$ & $24.9 \pm 4.01$ & $23.7 \pm 2.23$ & 0.278 \\
BSA $\left(\mathrm{m}^{2}\right)$ & $1.65 \pm 0.136$ & $1.81 \pm 0.129$ & 0.0025 \\
Systolic $(\mathrm{mmHg})$ & $145.2 \pm 15.4$ & $137.3 \pm 13.4$ & 0.131 \\
Diastolic $(\mathrm{mmHg})$ & $76.3 \pm 9.9$ & $79.9 \pm 11.9$ & 0.321 \\
Heart rate $(\mathrm{bpm})$ & $81.4 \pm 11.5$ & $78.9 \pm 13.3$ & 0.571 \\
Cardiovascular diseases & $15.40 \%$ & $40.70 \%$ & 0.193 \\
Hypertension & $69.20 \%$ & $51.90 \%$ & 0.310 \\
Diabetes & $38.50 \%$ & $11.10 \%$ & 0.0440 \\
Smoking & $15.40 \%$ & $92.60 \%$ & $5.4 \mathrm{E}-09$ \\
COPD & $7.70 \%$ & $3.70 \%$ & 0.599 \\
Hemoglobin $(\mathrm{g} / \mathrm{L})$ & $122.7 \pm 13.6$ & $130.0 \pm 16.9$ & 0.628 \\
TC $(\mathrm{mmol} / \mathrm{L})$ & $4.84 \pm 0.92$ & $4.47 \pm 1.29$ & 0.332 \\
TG (mmol/L) & $1.78 \pm 1.54$ & $1.23 \pm 0.74$ & 0.255 \\
HDL-C (mmol/L) & $1.14 \pm 0.31$ & $1.14 \pm 0.31$ & 0.9997 \\
LDL-C (mmol/L) & $3.11 \pm 0.83$ & $2.88 \pm 1.12$ & 0.484 \\
\hline COPD & &
\end{tabular}

COPD chronic obstructive pulmonary diseases, TC total cholesterol, TG triglyceride, $H D L-C$ high density lipoprotein cholesterol, $L D L-C$ low density lipoprotein cholesterol female AAAs were constructed based on the average of all male and female morphological parameters (Table 2) shown in Fig. 3a. In addition, the iliac bifurcation angle $(\phi)$ was chosen to be $60^{\circ}$ as which was confirmed having the least effect by Xenos et al. [21]. All the parameters of the two uniform models are presented in Table 2 and Fig. 3a.

The specific values of each size of the models

$l$ the length of the abdominal artery, $l_{1}$ the length of the infra-renal artery, $l_{2}$ the length of the common iliac artery, $\phi$ the angle of iliac bifurcation, $\varnothing A$ infra-renal artery diameters, $\varnothing B$ maximum diameters, $\varnothing C$ common iliac artery diameters

\section{Hemodynamic simulation}

1) Assumptions and governing equations

In this study, the blood was assumed to be incompressible, homogeneous, and Newtonian fluid, and the fluid domain was governed by the Navier-Stokes equation and the continuity equation [22]:

\section{a.}

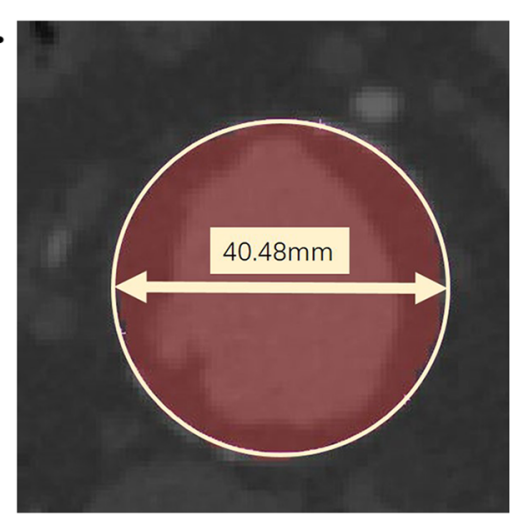

C.

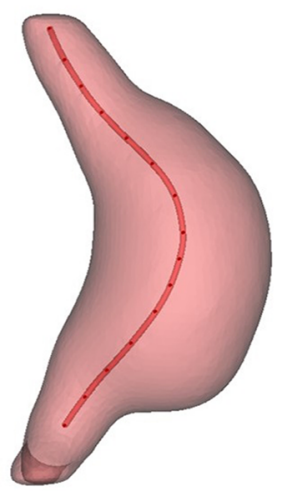

b.

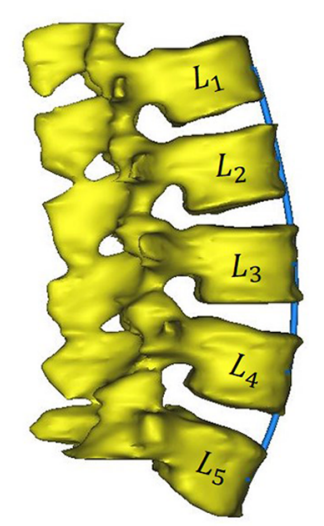

d.

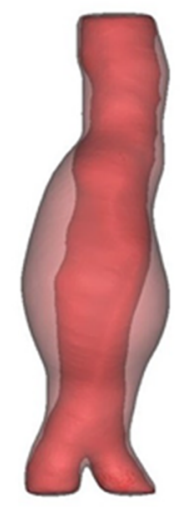

Fig. 2 Morphological feature parameters of AAA. a Diameter measurement. b Obtainment of lumbar vertebrae curve. Then, lumbar vertebrae curve was obtained by connecting the midpoint of the five lumbar vertebrae shown in dark blue. c Centerline acquisition. The centerline is in dark red. $\mathbf{d}$ Calculation of ILT percentage volume. The total volume of AAA is shown in pink and the volume of blood is shown in dark red 
Table 2 Model parameters

\begin{tabular}{lll}
\hline Parameters & Female & Male \\
\hline$I(\mathrm{~mm})$ & 99.5 & 106.2 \\
$I_{1}(\mathrm{~mm})$ & 61.47 & 72.84 \\
$I_{2}(\mathrm{~mm})$ & 55.8 & 71.34 \\
$\varphi\left(^{\circ}\right)$ & 60 & 60 \\
$\varnothing \mathrm{A}(\mathrm{mm})$ & 20.49 & 24.28 \\
$\varnothing B(\mathrm{~mm})$ & 48.35 & 52.50 \\
$\varnothing C(\mathrm{~mm})$ & 18.60 & 23.78 \\
\hline
\end{tabular}

$$
\begin{aligned}
& \rho\left[\frac{\partial \vec{u}}{\partial t}+(u \cdot \nabla) u\right]+\nabla p-\mu \nabla^{2} \vec{u}=0 \\
& \nabla \cdot \vec{u}=0
\end{aligned}
$$

where $\vec{u}$ and $p$ respectively represent fluid velocity vector and pressure. The density of blood $(\rho)$ was $1050 \mathrm{~kg}$. $\mathrm{m}^{-3}$ with constant viscosity $(\mu)$ of $0.0035 \mathrm{~Pa} \cdot \mathrm{s}$ [23, 24].The walls were considered to be rigid and no-slip. For continuity and velocity residuals, the convergence criterion was set to be $1 \times 10^{-5}$.
2) Mesh generation

The ICEM (ANSYS, Inc., Canonsbury, PA, USA) software was used to generate meshes of the models, with a combination of hexahedral and tetrahedral elements. The total number of elements in the uniform model for male is 456,303 and for female is 444,293 . The maximum and minimum dimensions of the mesh are 1.0 $\mathrm{mm}$ and $0.5 \mathrm{~mm}$, the number of the boundary layer was set to 5 , the height ratio was set to 1.1 , and the total height was set to $0.61051 \mathrm{~mm}$.

\section{3) Boundary conditions}

In order to study the performance of the models throughout the entire cardiac cycle, simulation calculations were carried out under pulsating blood flow conditions. The inlet velocity waveform and outlet pressure waveform are shown in Fig. 3b and c, from Olufsen et al. [25]. The pressure-velocity coupling was treated by the PISO [26] algorithm for the pulsatile flow. A second order upwind scheme [27] was employed for all convective diffusively transported variables. The simulations were performed for four cardiac cycles, with 200 steps in

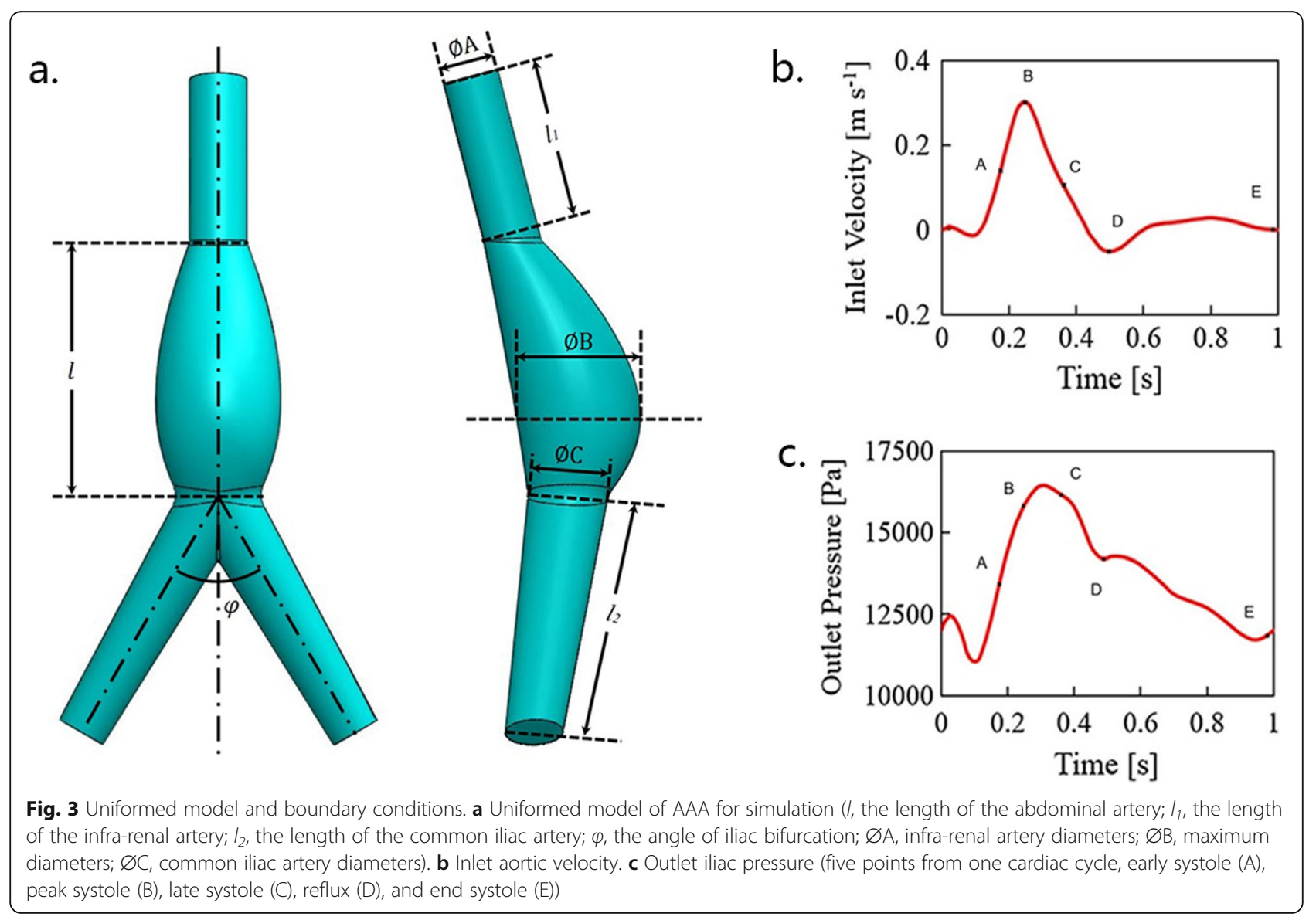


each cycle $(T=1 \mathrm{~s})$. The time-averaged results are then obtained by averaging the values calculated during the last complete period.

\section{Data analysis}

Statistical analysis was performed using the MATLAB programming environment (The Math-Works, Natick, Mass). The $\chi^{2}$ test was used to compare female and male groups, and a two-tailed $t$ test was used for gender comparisons. The probability level of $P<0.05$ was used to indicate statistical significance. The Tecplot software was used to calculate three wall shear stress (WSS)-based hemodynamic parameters for whole cardiac cycle. Their definition is based on a study by Chiastra et al. [28].

The time-averaged wall shear stress (TAWSS) was used to describe the features of WSS in pulsatile flow. The TAWSS was defined as follows:

$$
\text { TAWSS }=\frac{1}{\mathrm{~T}} \int_{0}^{T}|\mathrm{WSS}(s, t)| \cdot \mathrm{dt}
$$

where $T$ is the duration of the cardiac cycle and $s$ is the position on the vessel wall.

The oscillatory shear stress index (OSI) on the inner wall of the models was calculated as:

$$
\mathrm{OSI}=0.5\left[1-\left(\frac{\left|\frac{1}{T} \int_{0}^{T} \mathrm{WSS}(s, t) \cdot \mathrm{dt}\right|}{\frac{1}{T} \int_{0}^{T}|\mathrm{WSS}(s, t)| \cdot \mathrm{dt}}\right)\right]
$$

where WSS is a vector parameter and its direction changes with the cardiac cycle time. The OSI indicates the frequency of changes in the WSS direction, ranging from 0 (flow is one-directional without oscillations) to 0.5 (the WSS direction changes frequently).

The relative residence time (RRT) was calculated as:

$$
\mathrm{RRT}=\frac{1}{(1-2 \cdot \mathrm{OSI}) \mathrm{TAWSS}}
$$

RRT was used to determine the residence time of particles near the wall and recommended as single metric of low and oscillating shear stress. It is inversely proportional to the magnitude of the TAWSS vector and has obvious connections to the biological mechanisms of atherosclerosis.

\section{Results \\ Morphological parameter comparisons}

The morphological parameters are shown in Table 3. There was no significant difference in ASI $\left(0.0293 \mathrm{~m}^{-1}\right.$ for females and $0.0291 \mathrm{~m}^{-1}$ for males, $p=0.908$ ) and the expansion factor (2.39 for females and 2.22 for males, $p$ $=0.234$ ).

The volume of ILT and the percentage volume ILT of females were significantly smaller than males. The average ILT volume of females $\left(22491.66 \pm 15354.88 \mathrm{~mm}^{3}\right)$ was smaller than that of males $(53091.35 \pm 47030.15$ $\mathrm{mm}^{3}$ ) with $p=0.044$. And the ILT percentage volume, which eliminated the effect of body size, also showed that females have less ILT $(19.96 \% \pm 14.90 \%)$ compared with males $(37.48 \% \pm 21.14 \%)$ with $p=0.019$.

The averaged curvature of lumbar vertebrae curve and AAA centerline from female models was obviously higher than that of male. The results showed that female lumbar vertebrae has higher curvature $(0.01046 \pm$ $0.00407)$ than that of male $(0.00748 \pm 0.00240)$ with $p=$ 0.0113, shown in Fig. 4a, which was consistent with the study of Hay et al. [29]. The AAA centerlines of each case and the composite AAA curves (black lines) are shown in Fig. 4b. The curvature of the centerlines was $0.03809 \pm 0.01713$ for female and $0.02299 \pm 0.00668$ for male with $p=0.000753$.

\section{Hemodynamic simulation result}

Figure 5 a shows the distribution of pressure on the wall at the peak systole time $(v=0.33 \mathrm{~m} / \mathrm{s}$, point B in Fig. $3 \mathrm{~b})$, and the magnitude of the pressure is indicated by color. The distributions of pressure were similar between male and female, and the peak pressure was found on the low anterior areas of both AAA models. However, the peak pressure of the female model was much higher than that of the male model (female vs. male $=61.4$ vs. $46.3 \mathrm{~Pa}$ ).

Figure $5 \mathrm{~b}$ shows the distribution of the wall shear stress (WSS) at the peak systole time (point B). The contours indicate that male AAA model has a lower overall WSS compared to the female AAA, especially at the lower anterior area of the AAA. And the proportion of

Table 3 Morphological parameter comparisons

\begin{tabular}{llll}
\hline Gender & Female $(n=11)$ & Male $(n=23)$ & $p$ \\
\hline ASI $\left(\mathrm{m}^{-1}\right)$ & $0.0293 \pm 0.0037$ & $0.0291 \pm 0.0061$ & 0.908 \\
Expansion factor & $2.39 \pm 0.347$ & $2.22 \pm 0.616$ & 0.234 \\
Lumbar vertebrae curve & $0.01046 \pm 0.00407$ & $0.00748 \pm 0.00240$ & 0.0113 \\
AAA centerlines & $0.03809 \pm 0.01713$ & $0.02299 \pm 0.00668$ & $<0.01$ \\
ILT volume $\left(\mathrm{mm}^{2}\right)$ & $22491.66 \pm 15354.88$ & $53091.35 \pm 47030.15$ & 0.044 \\
ILT percentage volume & $19.96 \% \pm 14.90 \%$ & $37.48 \% \pm 21.14 \%$ & 0.019 \\
\hline
\end{tabular}




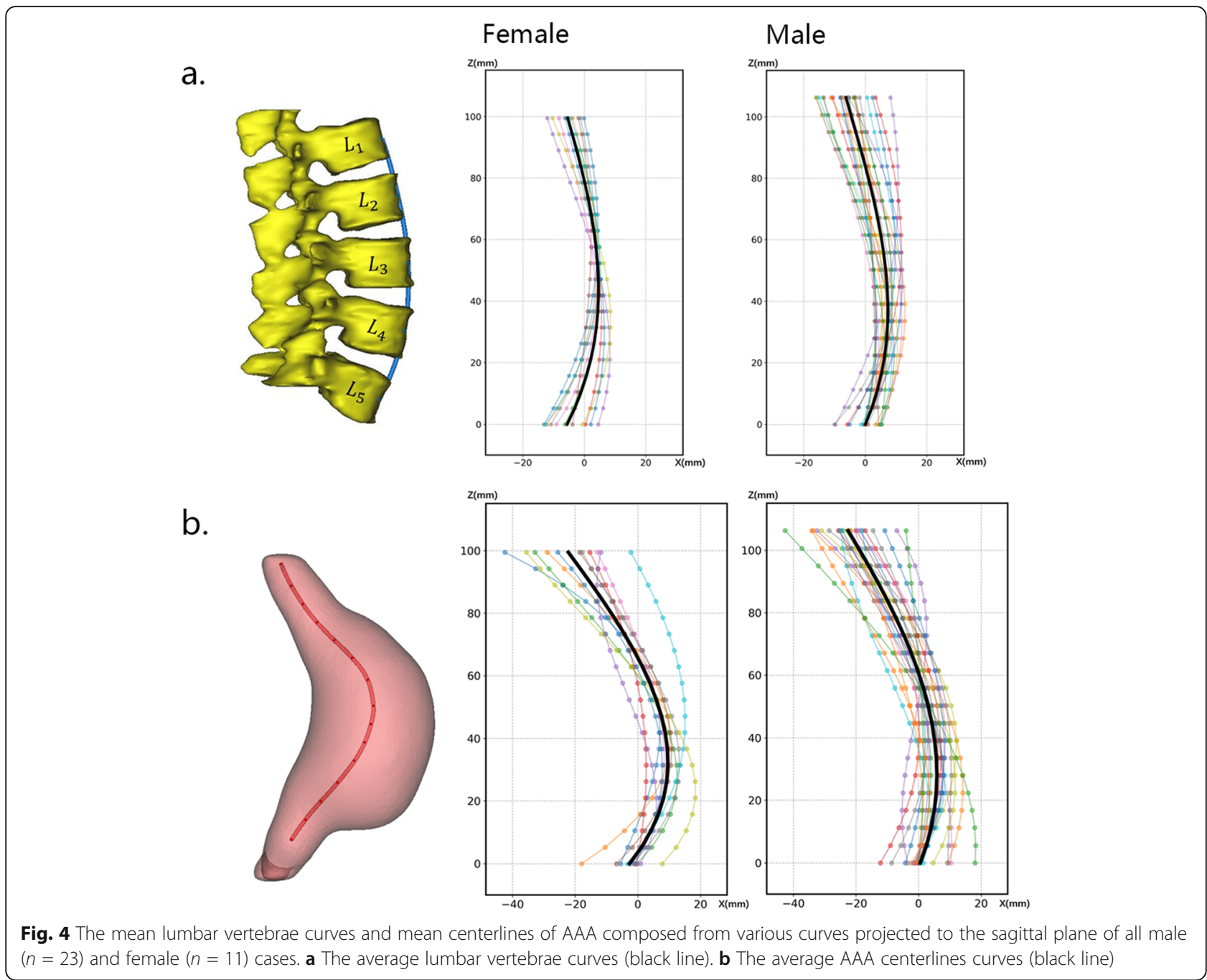

the area where the WSS of female AAA is less than 0.3 $\mathrm{Pa}$ is $27.069 \%$ and the WSS of male AAA is less than $0.3 \mathrm{~Pa}$ is $30.065 \%$.

For the time-averaged WSS (TAWSS) distribution, similar observations were made as for the abovedescribed WSS distribution. Figure $5 \mathrm{c}$ shows that the female model undertakes a smaller TAWSS during the entire cycle, but the difference is very small.

Figure $5 \mathrm{~d}$ shows the distribution of the OSI on gender models. Relatively high OSI aggregations are found on the low anterior and back areas of AAA models. The OSI on the wall of male AAA model $(0.333 \pm 0.0782)$ was generally higher than that on the female AAA model $(0.302 \pm 0.0782)$.

The contours of RRT for both genders as shown in Fig. 5e present the same features as the OSI distribution. The higher RRT mainly distributes at the lower anterior and back areas of both AAA models, and the RRT on the male AAA model was relatively higher than that on the female AAA model. As shown in Fig. 5e, the proportion of the red part $\left(\mathrm{RRT}>90 \mathrm{~Pa}^{-1}\right)$ of the female AAA model is less than that of males (female vs male = 4.93\%: $7.52 \%)$.

\section{Discussion}

Recent literatures have focused on the gender differences of cardiovascular diseases (CVDs) which initiates to raise awareness in research, clinical treatment, pharmacological development, device design, etc. for cardiovascular diseases [30]. So far, the uncovered reasons that may contribute to CVD gender differences are mainly related to different life habits and biological aspects, such as smoking, diabetes, hypertension, low/high density lipoprotein (LDL)-cholesterol levels, menopause, and hormone $[12,15,31]$. In the present study, morphological and hemodynamic differences between different genders were revealed by analyzing two groups of different gender AAA cases. These findings may provide new clues to the gender differences in CVDs. 


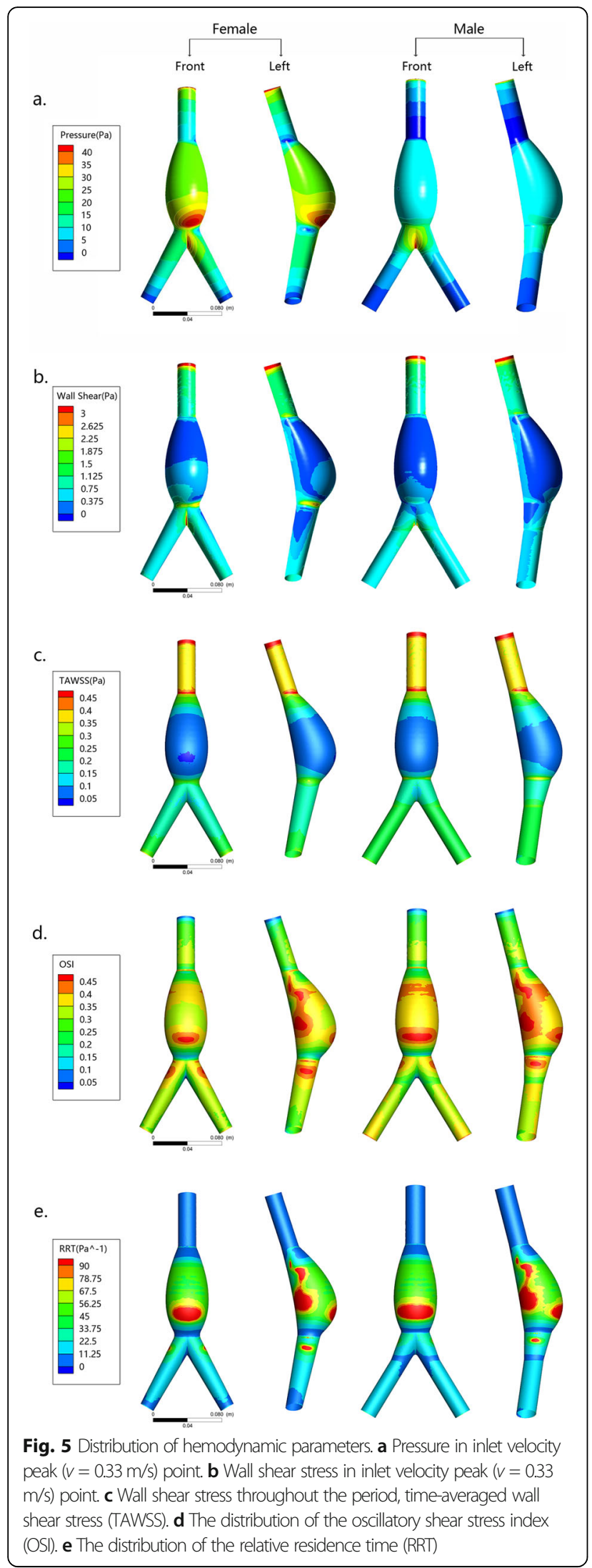

Morphological features are very important intuitive indicators of AAA risk. Currently, the maximum diameter is widely used as the criteria for EVAR surgery. In this study, we found that the female AAA model has more complex geometries (smaller diameters, larger ratio of max to normal diameter, shorter centerline, more curved centerline and lumbar vertebrae curvature) than the male. The hemodynamic simulation based on genderdifferent models revealed that the female AAA models experienced a more complex and dangerous hemodynamic environment. The series of hemodynamic indicators shown in the results confirm the hypothesis that the morphological differences could induce different hemodynamic environments, thereby increasing the risk of rupture for female AAA.

Besides, this study found that in the unified model of male AAA, low WSSs, high OSIs, and high RRTs are more likely to appear, which are indicators of ILT formation [32]. Our statistical results of thrombus volume also confirmed this speculation. Since the ILT was usually regarded as a mechanical cushion that can reduce AAA wall stress by a shielding effect and allow AAA to tolerate greater stress without rupture [33-36], it further proves that the hemodynamics in male AAA models is apt to keep the stability of AAA.

The hemodynamic characteristics of artery are obviously influenced by the geometry of the arteries. The abovementioned hemodynamic differences between the female and male models are likely to be formed by morphological differences (especially the different curvature of AAA centerlines). The reason for AAA centerline curvature difference may be explained anatomically. The abdominal aorta is anatomically adjacent to the lumbar vertebrae, which has already been confirmed here and documented by previous studies: the lumbar vertebrae curvature of female is higher than that of male [29]. The curvature of AAA centerline can generate asymmetry of the blood lumen, thereby increasing the nonuniform stress distribution and the risk of rupture.

It was widely reported that females with AAA less often meet the current anatomical criteria (maximum diameter $>5 \mathrm{~cm}$ ) for endovascular repair and experience worse perioperative and long-term survival [37]. Therefore, it is necessary to consider gender differences when evaluating AAA risk and seek more AAA indicators in addition to the current surgical criteria. According to current study, more morphological parameters besides the maximum diameter and hemodynamic factors are suggested to be involved.

It should be kept in mind that the CVDs are caused by multiple factors, like lifestyle, environment, gene, and hemodynamics, and so does the gender-difference of CVDs. Each factor could play roles together with one or several other factors. The present study added two new 
factors (morphology and hemodynamics) to this complicated problem, and their weights and exact roles in the entire story require more research to figure out.

As a preliminary study, there are still some shortcomings in this study. In this study, 11 female patients and 23 male patients were randomly selected as subjects of this study. Due to the patient specificity, greater numbers of patients are needed to be involved in the future study. In computational fluid dynamic (CFD) simulations, the AAA wall was considered to be rigid. This assumption may influence the magnitude but should not significantly affect the distribution of pressure and WSS [38]. Therefore, it should not affect the overall findings of our research.

\section{Perspectives and significance}

Gender differences in cardiovascular disease have received widespread attention, and studies of gender differences in AAA rupture risk are critical to the treatment of AAA patients and to reduce mortality of them. In this study, morphological and hemodynamic differences between genders were revealed by analyzing different gender AAA models, which may provide new clues to gender differences in cardiovascular disease. This paper points out that it is necessary to consider gender differences when assessing AAA risk and seek more AAA indicators in addition to the current surgical criteria (such as more morphological parameters besides the maximum diameter and hemodynamics factors).

\section{Conclusions}

The present study found that both the morphological and hemodynamic features have very obvious gender differences. The lumen of female AAA has smaller size (length and diameters), greater curvature, higher expansion ratio, and lower ILT volume. Female AAA models are subject to higher wall pressure, higher wall shear stress, and lower OSI (oscillatory shear). These morphological and hemodynamic indicators are likely to contribute to the higher rupture risk of AAA for female.

These findings would help to explore the mechanism of AAA gender differences together with other biological differences, and the conclusions draw more attention to gender-specific consideration of the treatment of AAA. More morphological and hemodynamic indictors are suggested to be involved in the future guidelines.

\section{Acknowledgements}

The authors wish to thank Yifeng Xi for helping to reconstruct $C T$ data and Yunqing Mu, Changcheng Yi, and Shuqi Ren for helping to count the volume and proportion of ILT.

\section{Authors' contributions}

Zujie Gao and Jiang Xiong made substantial contributions to the conception, design, and acquisition of the data, and drafting of the manuscript. Zengsheng Chen, Zaipin $\mathrm{Xu}$, and Xiaoyan Deng were involved in revising the manuscript critically for important intellectual content. Anqiang Sun and Yubo Fan were involved in the conception and design and revising the manuscript critically for important intellectual content. All authors gave final approval of the version to be published and agreed to be accountable for all aspects of the work in ensuring that questions related to the accuracy or integrity of any part of the work are appropriately investigated and resolved.

\section{Funding}

This work was supported by the National Natural Science Foundation of China (No. 11872096, 11472031, 11862004), and the "111"Project (B13003).

Availability of data and materials

Not applicable.

Ethics approval and consent to participate

The study has been approved by the Science and Ethics Committee of School of Biological Science and Medical Engineering of Beihang University.

Consent for publication

Not applicable

\section{Competing interests}

The authors declare that they have no competing interests.

\section{Author details}

${ }^{1}$ School of Biological Science and Medical Engineering, Beijing Advanced Innovation Center for Biomedical Engineering, Key Laboratory for Biomechanics and Mechanobiology of Ministry of Education, Beihang University, Beijing 100083, China. ${ }^{2}$ Department of Vascular and Endovascular Surgery, The Chinese PLA General Hospital, Beijing 100853, China. ${ }^{3}$ College of Animal Science, Guizhou University, Guiyang 550025, China. ${ }^{4}$ Key Laboratory of Rehabilitation Aids Technology and System of the Ministry of Civil Affairs, National Research Center for Rehabilitation Technical Aids, No. 1 Ronghuazhong Road, Beijing BDA, Beijing 100176, China.

Received: 23 February 2020 Accepted: 7 July 2020

Published online: 21 July 2020

\section{References}

1. Mosca L, Barrett-Connor E, Kass WN. Sex/gender differences in cardiovascular disease prevention: what a difference a decade makes. Circulation. 2011;124(19):2145-54.

2. Hafez H, Druce PS, Ashton HA. Abdominal aortic aneurysm development in men following a "normal" aortic ultrasound scan. Eur J Vasc Endovasc Surg. 2008;36(5):553-8.

3. Heikkinen $\mathrm{M}_{1} ., \mathrm{J}-\mathrm{P} \mathrm{S}$, Auvinen $\mathrm{O}$, . Ruptured abdominal aortic aneurysm in a well-defined geographic area. J Vasc Surg. 2002:36:2:291-296.

4. Lederle FA, Johnson GR, Wilson SE, Chute EP, Hye RJ, Makaroun MS, et al. The aneurysm detection and management study screening program: validation cohort and final results. Aneurysm Detection and Management Veterans Affairs Cooperative Study Investigators. Arch Intern Med. 2000; 160(10):1425-30.

5. Lindholt JS, Vammen S, Juul S, Fasting H, Henneberg EW. Optimal interval screening and surveillance of abdominal aortic aneurysms. Eur J Vasc Endovasc Surg. 2000;20(4):369-73.

6. Schmitz-Rixen T, Keese M, Hakimi M, Peters A, Böckler D, Nelson K, et al. Ruptured abdominal aortic aneurysm-epidemiology, predisposing factors, and biology. Langenbecks Arch Surg. 2016:401(3):275-88.

7. Sweeting MJ, Thompson SG, Brown LC, Powell JT. Meta-analysis of individual patient data to examine factors affecting growth and rupture of small abdominal aortic aneurysms. British J Surg. 2012;56(5):655-65.

8. Xenos M, Bluestein D. Biomechanical aspects of abdominal aortic aneurysm (AAA) and its risk of rupture: fluid structure interaction (FSI) studies. 2011;7: 181-220. https://doi.org/10.1007/8415_2011_72.

9. Fillinger MF, Raghavan ML, Marra SP, Cronenwett JL, Kennedy FE. In vivo analysis of mechanical wall stress and abdominal aortic aneurysm rupture risk. J Vasc Surg. 2002;36(3):589-97.

10. Venkatasubramaniam AK, Fagan MJ, Mehta T. Mylankal K, Ray B, Kuhan G, Chetter IC, McCollum PT. A comparative study of aortic wall stress using finite element analysis for ruptured and non-ruptured abdominal aortic 
aneurysms. Eur J Vasc Endovasc Surg 2004;28:2:168-176; doi: https://doi.org/ 10.1016/j.ejvs.2004.03.029.

11. Carmo M, Colombo L, Bruno A, Corsi FRM, Roncoroni L, Cuttin MS, et al. Alteration of elastin, collagen and their cross-links in abdominal aortic aneurysms. Eur J Vasc Endovasc Surg. 2002;23(6):543-9.

12. Villard C, Hultgren R. Abdominal aortic aneurysm: sex differences. Maturitas. 2018;109:63-9. https://doi.org/10.1016/j.maturitas.2017.12.012.

13. Manning MW, Cassi LA, Jing H, Szilvassy SJ, Alan D. Abdominal aortic aneurysms: fresh insights from a novel animal model of the disease. Vasc Med. 2002;7(1):45-54.

14. Kimura M, Hoshina K, Miyahara K, Nitta J, Kobayashi M, Yamamoto S, et al. Geometric analysis of ruptured and nonruptured abdominal aortic aneurysms. J Vasc Surg. 2019;69(1):86-91. https://doi.org/10.1016/j.jvs.2018. 04.035.

15. Lo RC, Lu B, Conrad MF, Fillinger MF, Matyal R, Hamdan AD, et al. Relative importance of aneurysm diameter and body size for predicting AAA rupture in men and women. J Vasc Surg. 2013:57(1):287-8.

16. McAdams MA, Van Dam RM, Hu FB, Dam V. Comparison of self-reported and measured BMI as correlates of disease markers in U.S. adults. Obesity. 2012;15(1):188.

17. De Rango P, Farchioni L, Fiorucci B, Lenti M. Diabetes and abdominal aortic aneurysms. Eur J Vasc Endovasc Surg. 2014;47(3):243-61. https://doi.org/10. 1016/j.juvs.2013.12.007.

18. Brewster DC, Cronenwett JL, Hallett JW, Johnston KW, Krupski WC, Matsumura JS. Guidelines for the treatment of abdominal aortic aneurysms. Report of a subcommittee of the Joint Council of the American Association for Vascular Surgery and Society for Vascular Surgery. J Vasc Surg. 2003; 37(5):1106-17.

19. Molla FL, Fraedrich G, Verzini F, Haulon S, Waltham M, Herwaarden JAV, et al. Management of abdominal aortic aneurysms clinical practice guidelines of the European Society for Vascular Surgery. Eur I Vasc Endovasc Surg. 2011;41(Suppl 1):S1-S58.

20. Davies RR, Amy G, Coady MA, George T, Botta DM, Brendan B, et al. Novel measurement of relative aortic size predicts rupture of thoracic aortic aneurysms. Ann Thorac Surg. 2006;81(1):169-77.

21. Michalis X, Yared A, Dan Z, Shmuel E, Ricotta JJ, Nicos L, et al. The effect of angulation in abdominal aortic aneurysms: fluid-structure interaction simulations of idealized geometries. Med Biol Eng Comput. 2010;48(12): $1175-90$.

22. Wang Z, Sun A, Fan Y, Deng X. Comparative study of Newtonian and nonNewtonian simulations of drug transport in a model drug-eluting stent. Biorheology. 2012;49(4):249-59.

23. Shahcheraghi N, Dwyer HA, Cheer AY, Barakat Al, Rutaganira T. Unsteady and three-dimensional simulation of blood flow in the human aortic arch. J Biomech Eng. 2002;124(4):378-87.

24. Oshima M, Torii R, Kobayashi T. Finite element simulation of blood flow in the cerebral artery. Comput Methods Appl Mech Eng. 2001;191(6/7):661-71.

25. Olufsen MS, Peskin CS, Kim WY, Pedersen EM, Nadim A, Larsen J. Numerical simulation and experimental validation of blood flow in arteries with structured-tree outflow conditions. Ann Biomed Eng. 2000;28(11):1281-99.

26. Issa Rl. Solution of the implicitly discretised fluid flow equations by operator-splitting. J Comput Phys. 1991;62(1):40-65.

27. Antiga L, Ene-lordache B, Remuzzi A. Computational geometry for patientspecific reconstruction and meshing of blood vessels from MR and CT angiography. IEEE Transactions Med Imaging. 2003;22(5):674-84.

28. Chiastra C, Morlacchi S, Gallo D, Morbiducci U, Cardenes R, Larrabide I, Migliavacca F. Computational fluid dynamic simulations of image-based stented coronary bifurcation models. J Royal Soc Interface. 2013;10:84: 20130193. https://doi.org/10.1098/rsif.2013.0193.

29. Hay O, Dar G, Abbas J, Stein D, May H, Masharawi Y, Peled N, Hershkovitz I. The lumbar lordosis in males and females, revisited. PLOS ONE. 2015;10(8): e0133685. https://doi.org/10.1371/journal.pone.0133685.

30. Appelman Y, van Rijn BB, Ten Haaf ME, Boersma E, Peters SA. Sex differences in cardiovascular risk factors and disease prevention. Atherosclerosis. 2015;241(1):211-8. https://doi.org/10.1016/j.atherosclerosis. 2015.01.027.

31. Lindquist Liljeqvist M, Hultgren R, Siika A, Gasser TC, Roy J. Gender, smoking, body size, and aneurysm geometry influence the biomechanical rupture risk of abdominal aortic aneurysms as estimated by finite element analysis. J Vasc Surg. 2017;65(4):1014-21.
32. Gallo D, Steinman DA, Bijari PB, Morbiducci U. Helical flow in carotid bifurcation: a surrogate marker of exposure to abnormal shear? J Biomech 2012;45(supp-S1):S148.

33. Li ZY, U-King-Im J, Tang TY, Soh E, See TC, Gillard JH. Impact of calcification and intraluminal thrombus on the computed wall stresses of abdominal aortic aneurysm. J Vasc Surg. 2008;47(5):928-35.

34. Wang DHJ, Makaroun MS, Webster MW, Vorp DA. Effect of intraluminal thrombus on wall stress in patient-specific models of abdominal aortic aneurysm is. J Vasc Surg. 2002;36(3):598-604.

35. Vorp DA, Mandarino WA, Webster MW, Gorcsan J. Potential influence of intraluminal thrombus on abdominal aortic aneurysm as assessed by a new non-invasive method. Cardiovasc Surg. 1996;4(6):732-9.

36. Dam EAV, Dams SD, Peters GWM, Rutten MCM, Schurink GWH, Buth J, et al. Non-linear viscoelastic behavior of abdominal aortic aneurysm thrombus. Biomech Model Mechanobiol. 2008;7(2):127-37.

37. O'Donnell TFX, Verhagen HJ, Pratesi G, Pratesi C, Teijink JAW, Vermassen FEG, et al. Female sex is associated with comparable 5-year outcomes after contemporary endovascular aneurysm repair despite more challenging anatomy. J Vasc Surg. 2019;71(4):1179-89.

38. Drewe CJ, Parker LP, Kelsey LJ, Norman PE, Powell JT, Doyle BJ. Haemodynamics and stresses in abdominal aortic aneurysms: a fluidstructure interaction study into the effect of proximal neck and iliac bifurcation angle. J Biomech. 2017;60:150-6. https://doi.org/10.1016/j. jbiomech.2017.06.029.

\section{Publisher's Note}

Springer Nature remains neutral with regard to jurisdictional claims in published maps and institutional affiliations.

Ready to submit your research? Choose BMC and benefit from:

- fast, convenient online submission

- thorough peer review by experienced researchers in your field

- rapid publication on acceptance

- support for research data, including large and complex data types

- gold Open Access which fosters wider collaboration and increased citations

- maximum visibility for your research: over $100 \mathrm{M}$ website views per year

At $\mathrm{BMC}$, research is always in progress.

Learn more biomedcentral.com/submissions 